\title{
Empreendedorismo como possível ferramenta de auxílio ao desenvolvimento das cidades*
}

\section{Entrepreneurship as a potential tool for support to development of cities}

Marília Ribas Machado

Andressa Sasaki Vasques Pacheco ${ }^{2}$ Pedro Antônio de Melo $^{3}$
Recebido em: 31/10/2016. Aprovado em: 23/03/2017.

1 Mestranda do curso de Administração da Universidade Federal de Santa Catarina. Atua como bolsista do pojeto de pesquisa intitulado Planejamento Estratégico em Universidades Públicas Brasileiras: modelos e práticas de gestão universitária. Também atua como bolsista do projeto de extensão intitulado Curso de Atualização em Gestão e Liderança para servidores do Insituto Federal de Santa Catarina. Trabalha como pesquisadora do Instituto de Pesquisas e Estudos em Administração Universitária (INPEAU).

2 Doutora em Engenharia e Gestão do Conhecimento - UFSC. Professora do Programa de Pós-graduação em Administração e do Programa de Pós-graduação em Administração Universitária. Participante dos grupos de pesquisa INPEAU Instituto de Pesquisas e Estudos em Administração Universitária e NEOGAP - Núcleo Estudos e Observação de Gestão, Aprendizagem e Pessoas.

3 Doutor em Engenharia de Produção e Sistemas, pela Universidade Federal de Santa Catarina, e pós-doutorado em Educação Superior, pelo Instituto Internacional para a Educação Superior na América Latina e o Caribe - IESALC, da Unesco. É Doutor Honoris Causa, pela Honorable Academia Mundial de Educación - HAME (2012). É professor da UFSC - Universidade Federal de Santa Catarina, no Departamento de Ciências da Administração - CAD.

\section{Resumo}

O presente estudo teve o propósito de analisar possíveis desenvolvimentos advindos da implantação dos polos de ensino a distância dos cursos de Administração, Ciências Contábeis e Ciências Econômicas da Universidade Federal de Santa Catarina nos estados do Paraná, Rio Grande do Sul e Santa Catarina com o objetivo de descrever a percepção dos coordenadores e tutores dos polos sobre as características empreendedoras, além de descrever possíveis mudanças nas dinâmicas econômicas, sociais e populacionais das cidades as quais contém os polos. $\mathrm{O}$ trabalho trata de um estudo descritivo, qualitativo e bibliográfico que foi possível ser realizado por meio do auxílio de um questionário enviado pela internet aos tutores e coordenadores dos polos de educação a distância. Dentre a obtenção dos principais resultados após o advindo da educação a distância para as cidades observadas, foi perceptível mudança em relação à evolução educacional, além de mudanças nas dinâmicas sociais, populacionais e econômicas entre as cidades observadas, corroborando o propósito geral do trabalho mostrando cada vez mais que uma das explicações para a promoção do desenvolvimento é a educação.

Palavras-chave: Educação a distância. Empreendedorismo. Desenvolvimento.

\section{Abstract}

This study aimed to examine possible developments arising from the implementation of educational centers distance of Business Administration courses, Accounting and Economics from the Federal University of Santa Catarina in the states of Paraná, Rio Grande do Sul and Santa Catarina in order to describe the perception of coordinators and tutors of the poles on the entrepreneurial characteristics, and describe possible changes in economic, social and population dynamics of the cities which contains the poles. The work is a descriptive, qualitative and bibliographic study it was possible to be accomplished by means of a questionnaire sent by the internet to tutors and coordinators of distance education centers. Among the achievement of the main results after arising from the distance to the observed cities, was perceptible change in relation to educational development, as well as changes in social dynamics, economic and population between obervadas cities, corroborating the general purpose of showing work increasingly that one explanation for the promotion of development is education.

Keywords: Distance education. Entrepreneurship. Development. 


\section{Introdução}

A educação a distância tem se tornado cada vez mais adotada entre as pessoas de diversas regiões do país. Teve sua ascensão a partir do século XX, tornando-se capaz de oferecer programas de formação profissional e permanecendo até os dias atuais com as mais variadas formas de ensino, seja formação superior, especialização, qualificação, formação técnica, entre tantos outros modelos presentes no país.

Souza (2012), em uma pesquisa realizada pela Associação Brasileira de Educação a Distância (ABED), compõe os motivos de os alunos optarem pela educação a distância:

- Os acadêmicos querem, apenas, ter um diploma de nível superior, justificando que será importante para realizar concursos públicos que exijam a diplomação mínima de graduado;

- Os acadêmicos desejam entrar no mercado de trabalho, afirmando que este está muito competitivo, exigindo, no mínimo, uma graduação como pré-requisito para pleitear um cargo com uma razoável remuneração;

- Além de outros objetivos diversos tais como: ampliação, qualificação e atualização do conhecimento; exigência, por parte da empresa em que trabalha, pois é necessário um curso superior para o desenvolvimento da atividade profissional dentro da organização; realização pessoal e profissional.

Seja pelos mais variados motivos, a educação a distância faz-se cada vez mais presente e atuante no país. Assim, como é do conhecimento de todos que as capitais estão saturadas de tantas iniciativas empresariais, por esse motivo, o desenvolvimento de cidades mais afastadas de grandes centros faz-se necessário, fazendo com que o desenvolvimento de pequenas regiões seja significativo.

Por fim, este estudo tem o objetivo de analisar possíveis desenvolvimentos advindos da implantação dos polos de ensino superior dos cursos de Administração, Ciências Contábeis e Ciências Econômicas da Universidade Federal de Santa Catarina, de forma que a pesquisa sirva como uma bússola para guiar a instituição, possibilitando a melhora e atualização dos procedimentos ado-

\section{Metodologia}

Esta pesquisa classifica-se como, predominantemente, descritiva e qualitativa, bibliográfica.

Quanto aos objetivos propostos, o trabalho se classifica como descritivo, pois o estudo tem como intuito descrever o possível desenvolvimento por meio do empreendedorismo que o ensino a distância dos cursos de Administração, Ciências Contábeis e Ciências Econômicas da Universidade Federal de Santa Catarina proporcionara para as cidades onde há polos de apoio presencial.

Levando-se em consideração a classificação de Gil (2008), em relação aos procedimentos técnicos, pode-se considerar que a pesquisa foi bibliográfica e levantamento de dados. Bibliográfica porque a realização da fundamentação teórica da pesquisa foi embasada em conceitos sobre o histórico e impacto da educação a distância, bem como os conceitos acerca do desenvolvimento local.

Para a coleta de dados realizada entre os meses de maio e junho do ano, utilizou-se o questionário com perguntas abertas e de múltipla escolha, desenvolvido pelo Google Docs de modo on-line, uma vez que a análise seria direcionada a pessoas fora do estado de Santa Catarina, optou-se pela internet como o meio mais eficaz e disponível no momento para obter as informações e dar andamento no estudo.

Conforme Marconi e Lakatos (2003, p. 201), “o questionário é um instrumento de coleta de dados, constituído por uma série de perguntas, que devem ser respondidas por escrito e sem a presença do entrevistador”.

Segundo Barbetta (2002), a população é um conjunto dos elementos que se deseja estudar e a amostra é um subconjunto da população.

Nesta pesquisa, a população foi caracterizada por coordenadores e tutores dos polos dos cursos de graduação em Administração, Ciências Contábeis e Ciências Econômicas na modalidade a distância da Universidade Federal de Santa Catarina, dos estados do Paraná, Rio Grande do Sul e de Santa Catarina, tendo como população-alvo 62 participantes, porém, neste estudo, obtiveram-se 30 respostas para a amostra, ou seja, 48,39\% do total, portanto, está a população acessível.

\section{Histórico EAD (UAB) no Brasil}

O Sistema Universidade Aberta do Brasil (UAB) é um sistema integrado entre universidades públicas, sen- 
do considerada uma importante iniciativa para inclusão de jovens, com difícil acesso à formação universitária.

O sistema foi oficializado pelo decreto $\mathrm{n}^{\circ} 5.800 \mathrm{de}$ 8 de junho de 2006,

Art. $1^{\circ}$ Fica instituído o Sistema Universidade Aberta do Brasil - UAB, voltado para o desenvolvimento da modalidade de educação a distância, com a finalidade de expandir e interiorizar a oferta de cursos e programas de educação superior no País. Parágrafo único. São objetivos do Sistema UAB: I - oferecer, (prioritariamente, cursos de licenciatura e de formação inicial e continuada de professores da educação básica; [...] IV - ampliar o acesso à educação superior pública; [...]. (BRASIL, 2006).

Em relação a oferta do EAD, segundo Litto e Formiga (2009), a alternativa para atendimento às demandas por educação superior no país contribuirá para o enfrentamento de um cenário nacional de assimetrias educacionais, seja em relação à oferta de cursos superiores, seja em relação às possibilidades de oferta de educação continuada ao longo da vida.

Desse modo, funciona como um eficaz instrumento para a universalização do acesso ao ensino superior e para a requalificação do professor em outras disciplinas, fortalecendo a escola no interior do Brasil, minimizando a concentração de oferta de cursos de graduação nos grandes centros urbanos e evitando o fluxo migratório para as grandes cidades.

Os cursos oferecidos pela UAB são baseados nas estruturas de polos. Para que seja possível oferecer um curso na EaD, é necessário que se tenha um polo de apoio presencial nas cidades ou próximos as cidades que serão ofertados os cursos. De acordo com o portal da CAPES (2015), o polo é uma estrutura acadêmica de apoio pedagógico, tecnológico e administrativo às atividades de ensino e aprendizagem dos cursos e programas de EaD de responsabilidade das instituições públicas de ensino superior.

\subsection{Impactos da Educação a Distância}

Pode-se considerar que a educação a distância é considerada uma das formas mais democráticas de modalidades de educação, pois é capaz de atender a diversas pessoas simultaneamente.

A educação a distância atende a vários propósitos. Do indivíduo que procura sua primeira qualificação na educação superior ao indivíduo aposentado que busca uma forma de educação continuada e engajamento social. (SANTOS, 2009).
Conforme Santos (2009, p. 291), "a educação a distância proporciona oportunidades iguais a indivíduos que vivem nos locais mais distantes ou de difícil acesso à educação tradicional".

Porém, para que haja uma educação a distância de qualidade e inovadora, faz-se necessário um aparato tecnológico para que a comunicação seja eficiente quando for requisitada.

As Tecnologias da Informação e Comunicação (TICs), de acordo com Santos (2009), relativizaram os conceitos de espaço geográfico e tempo, reduzindo, virtualmente, as distâncias globais e otimizando o tempo gasto para acessar o vasto acervo da produção cultural da humanidade.

Em concordância, essa nova maneira de ensinar demanda muita dedicação e esforço dos alunos, pois o processo de autoestudo está intimamente ligado ao seu desempenho, uma vez que encontrará seus professores poucas vezes no semestre. Por isso, faz-se necessário o total engajamento do aluno com as disciplinas e com os materiais disponibilizado através das TICs.

Por fim, seguindo o modo de produção de sociedade do conhecimento, em breve é possível que não se façam mais distinções entre formação inicial e formação continuada, pois na $\mathrm{EaD}$ o método não distingue do conteúdo. (SANTOS, 2009).

\subsection{Desenvolvimento Local}

O desenvolvimento local busca, basicamente, a reativação da economia e dinamização de uma sociedade local, com base nos recursos da própria localidade, incentivando o crescimento da economia, criação de emprego e qualidade de vida local.

Essa dinamização pode ser caracterizada pela presença de dinâmicas econômicas, populacionais/demográficas e sociais. De acordo com Bonelli (2001), as dinâmicas econômicas estão relacionadas ao nível de renda e emprego, as dinâmicas demográficas relacionadas a movimentos populacionais e urbanização.

Segundo Rozas (1998 apud MARTINS, 2002), o desenvolvimento local é a organização comunitária em torno de um planejamento para o desenvolvimento, por uma perspectiva de construção social, constituindo, assim, um instrumento fundamental, de caráter orientador e condutor, de superação da pobreza. Não se trata, contudo, de buscar tão somente o atendimento às carências materiais, mas a identificação e a promoção das qualida- 
des, capacidades e competências existentes na comunidade e no lugar. Mas a superação das piores manifestações da pobreza na atualidade requer, igualmente, uma revisão de conceitos e, sobretudo, de posturas.

De acordo com Buarque (2008), para que o desenvolvimento local seja consistente, ele deve mobilizar e explorar as potencialidades locais e contribuir para elevar as oportunidades sociais e a viabilidade e competitividade da economia local.

Pode-se dizer que para um desenvolvimento local sustentável é necessário que haja diversas ações para quebrar a inércia do subdesenvolvimento.

De maneira geral, o desenvolvimento local é um conjunto da comunidade local, pois o apoio fornecido é de profunda importância e relevância para o desenvolvimento local e os agentes dessa mudança de certa forma estarão mais estimulados.

\subsubsection{Educação e Desenvolvimento}

A educação é a palavra que define o desenvolvimento por proporcionar o acesso igualitário de direitos e a ascensão socioeconômica de classes sociais menos privilegiadas, ou seja, a educação, juntamente à união de diversos fatores sociais pode promover empoderamento dos que a adquirem.

Entretanto, por meio da educação, podemos de saída compreender o que é o poder na sociedade, iluminando as relações de poder que a classe dominante torna obscura. Também podemos nos preparar e participar de programas para mudar a sociedade (FREIRE; SHOR, 2013).

Santos (1970) defende que não se pode atingir o desenvolvimento somente pela educação e mesmo essa mão tem maior sucesso se toda uma gama de ações econômicas, de saúde, de vida social não forem deflagradas em simultaneidade.

Corroborando, a união de fatores condicionantes para o acesso da educação, Santos (1970) discorre que não é possível que todo o desenvolvimento seja decorrência, unicamente, da educação, mas não será certo que se deixe a educação como processo isolado, desarticulado das metas econômicas da sociedade.

Por fim, pode-se perceber que, inevitavelmente, para que haja desenvolvimento, é necessário que a educação seja vista como uma alternativa de investimento, porém. essa alternativa não deve ser vista como a única as dimensões econômicas e de saúde agindo em conjunto em conformidade podem proporcionar o verdadeiro desenvolvimento social e econômico de uma população.

\section{Resultados e análise dos dados}

Neste tópico encontra-se a apresentação e análise dos dados desenvolvidos no decorrer do estudo. Na análise em relação, a pesquisa realizada foi possível obter 30 respostas e obtiveram-se os seguintes resultados:

Figura 1 - Mudanças pessoais/profissionais percebidas no comportamento dos acadêmicos após o ingresso na universidade

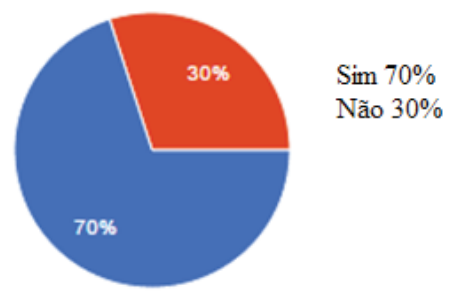

Fonte: Elaborado pelos autores.

Em relação às mudanças pessoais/profissionais percebidas entre os acadêmicos, 21 respondentes, (70\%) afirmaram ter percebido mudanças pessoais/profissionais dos acadêmicos após o ingresso na universidade, enquanto, apenas, 7 entrevistados (30\%), alegaram não ter percebido as alterações pessoais/profissionais.

Figura 2- O auxílio da graduação na busca de especializações ou outras qualificações

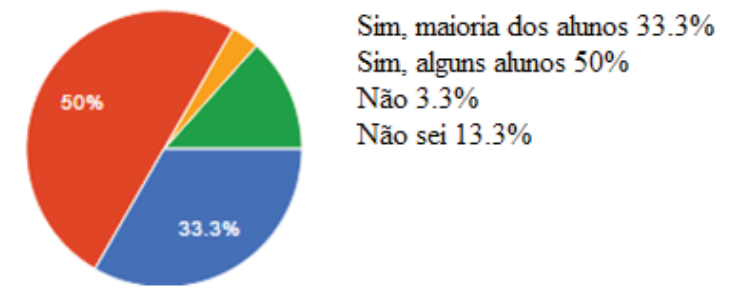

Fonte: Elaborado pelos autores.

Em relação à busca dos acadêmicos por novas qualificações ou especializações, pode-se observar que 15 respondentes, (50\%) afirmaram que, apenas, alguns alunos buscaram novas qualificações, 10 entrevistados, $(33,3 \%)$ alegaram que a maioria dos acadêmicos buscaram realizar especializações ou buscaram por qualificações, enquanto 4 respondentes $(13,3 \%)$ não souberam afirmar se os acadêmicos buscaram ou não novas qualificações ou funções, e, apenas, 1 entrevistado (3,3\%) afirmou que não houve busca por especializações dos acadêmicos. 
Figura 3- Percepção de alteração nas dinâmicas econômica das cidades

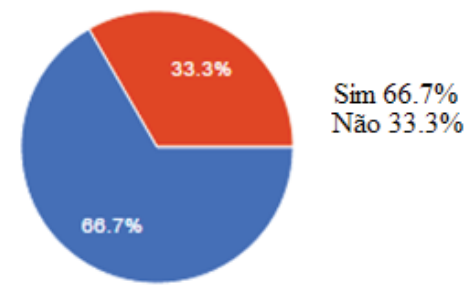

Fonte: Elaborado pelo autor.

Em relação à percepção de alteração nas dinâmicas econômicas das cidades, 20 entrevistados (66,7\%) afirmaram ter percebido alguma alteração nas dinâmicas econômicas da cidade após a implantação do EaD. Por outro lado, 10 respondentes, $(33,3 \%)$ afirmaram não ter percebido nenhuma alteração nas dinâmicas econômicas da cidade.

Figura 4- Percepção de alteração nas dinâmicas sociais das cidades

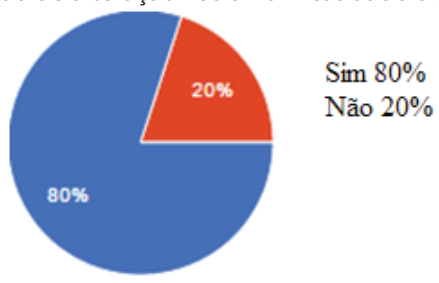

Fonte: Elaborado pelo autor.

Quando questionados sobre mudanças que o $\mathrm{EaD}$ trouxe na cidade quanto às dinâmicas sociais, 24 respondentes (80\%) afirmaram perceber as mudanças sociais após a instalação do polo EaD na cidade. Por outro lado, 6 entrevistados, (20\%) informaram não ter notado mudanças na dinâmica sociais da sociedade com a chegada do polo $\mathrm{EaD}$ na região.

Figura 5- Evento, política, ou dinâmica na região, que modificou a estrutura e a dinâmica da cidade após a instalação do polo EaD

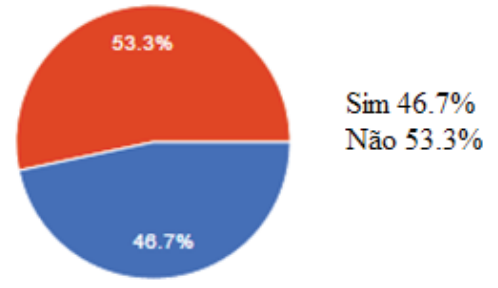

Fonte: Elaborado pelo autor.

Em seguida, os coordenadores e tutores responderam se existe algum outro evento, política, ou dinâmica na região, que modificou ou pode ter modificado a estrutura e a dinâmica da cidade. 16 entrevistados (53,3\%) afirmaram que não ocorreu nenhum evento ou dinâmica de grande porte, de modo a modificar a estrutura ou dinâmica da cidade, por outro lado, 14 respondentes, $(46,6 \%)$, afirmaram que ocorreram alguns eventos modificando a estrutura e a dinâmica da cidade.

Entre as modificações citadas, estão:

- Em Chapecó, houve a instalação do campus da Universidade da Fronteira Sul - UFFS;

- Em Blumenau houve a abertura de novas empresas, universidades e festas regionais;

- Na cidade de Cruzeiro do Oeste houve o aumento no número de instituições de ensino superior, facilitando o acesso a educação;

- Na cidade de Tapejara houve um aumento considerável no número de indústrias;

- Em Seberi, houve, recentemente, a inauguração de um frigorífico em uma das cidades, com expectativa de gerar até 2 mil empregos até 2018, sendo necessário, inclusive, mão de obra de outras regiões, o que deve gerar, consequentemente, crescimento imobiliário e populacional na região.

\section{Considerações finais}

De maneira geral, pode-se dizer que a implantação dos polos de educação a distância pode ter sido um dos fatores decorrentes que proporcionaram impacto nas dinâmicas sociais, econômicas e populacionais nas cidades que possuem polo de apoio presencial como, por exemplo, a ampliação do comércio local e da estrutura imobiliária (casas e hotéis), a análise, também, permitiu observar que houve aumento do número de ruas pavimentadas, melhoria na sinalização e iluminação das cidades, além da instalação de outras IES (públicas e privadas) e da instalação de indústrias nas cidades devido ao aumento de mão de obra especializada, tornando as cidades atrativas para instalação de empresas.

Portanto, após as análises e interpretação dos dados, pode-se concluir que o presente estudo teve seus objetivos alcançados, uma vez que foi perceptível o avanço nas questões econômicas, educacionais e sociais dentre os municípios analisados.

\section{Referências}

BARBETTA, Pedro Alberto. Estatística aplicada às ciências sociais. 5. ed. Santa Catarina: UFSC, 2002. 
BONELLI, Regis. Impactos econômicos e sociais de longo prazo da expansão agropecuária no Brasil: revolução invisível e inclusão social. 2001. Disponível em: <http:// repositorio.ipea.gov.br/bitstream/11058/2159/1/TD_838. pdf>. Acesso em: 20 jun. 2015.

BUARQUE, Sergio C. Construindo o desenvolvimento local sustentável: metodologia de planejamento. 4. ed. Rio de Janeiro: Garamond, 2008. Disponível em: <http://books.google. com.br/books?hl=pt- BR\&lr;=\&id=UDzMIAm2ldwC\&oi=fnd\&pg=PA11\&dq=DESENVOLVIMENTO+LOCAL\&ot$\mathrm{s}=\mathrm{fj6DBKNPez \& sig=IlModL}$ _doigBSvWkEv5Mh7u2U6Q\#$\mathrm{v}=$ onepage $\& \mathrm{q}=$ DESENVOLVIMENTO LOCAL\&f=false $>$. Acesso em: 20 abr. 2015.

BRASIL. Decreto no 5.622, de 19 de dezembro de 2005. Regulamenta o art. 80 da Lei no 9.394, de 20 de dezembro de 1996, que estabelece as diretrizes e bases da educação nacional. Disponível em: <http://www.planalto.gov.br/ccivil_03/_ato20042006/2005/decreto/d5622.htm>.

BRASIL. Decreto no 5.800, de 8 de junho de 2006. Dispõe sobre o Sistema Universidade Aberta do Brasil - UAB. Disponível em: < http://www.planalto.gov.br/ccivil_03/_ato20042006/2006/decreto/d5800.htm>.

FREIRE, Paulo; SHOR, Ira. Medo e ousadia: o cotidiano do professor. Rio de Janeiro: Paz e Terra, 2013. Disponível em: <https://books.google.com.br/books?id=_rzNAgAAQBAJ\&pg=PT56\&dq=através + da + educação, + podemos + de + saída+compreender+o+que+é + o+poder + na + sociedade, + iluminando+as+relações + de + poder + que $+a+$ classe + dominante+torna+obscuras.\&hl=pt-BR\&sa=X\&ei=sTgkVYKIK8ecNo6OgLAL\&ved=0CB0Q6AEwAA\#v=onepage\&q\&f;=false>. Acesso em: 20 abr. 2015.
GIL, Antonio Carlos. Como elaborar projetos de pesquisa. 4. ed. São Paulo: Atlas, 2008.

LITTO, Fredric M.; FORMIGA, Marcos (Org.). Educação a distância: o estado da arte. São Paulo: Pearson, 2009.

MARCONI, M. de A.; LAKATOS, E. M. Fundamentos da metodologia científica. São Paulo: Atlas, 2003.

MARTINS, Sérgio Ricardo Oliveira. Desenvolvimento local: questões conceituais e metodológicas. Revista Internacional de Desenvolvimento Local, Campo Grande, v. 3, n. 5, p. 51-59, set. 2002. Disponível em: <http://www. ufpa.br/epdir/images/docs/paper74.pdf > . Acesso em: 28 jun. 2015.

SANTOS, Silvio Coelho dos. Um esquema para a educação em Santa Catarina. Florianópolis: EDEME, 1970.

SANTOS, Andeia Inamorato dos. O conceito de abertura em EaD. In: LITTO, Fredric M.; FORMIGA, Marcos (Org.). Educação a distância: o estado da arte. São Paulo: Pearson Education Brasil, 2009.

SOUZA, Lourivan Batista de. Educação Superior a Distância: O perfil do "Novo" Aluno Sanfranciscano. Revista Brasileira de Aprendizagem Aberta e A Distância, São Paulo, v. 11, p. 1-13, 2012. Disponível em: <http://www. abed.org.br/revistacientifica/Revista_PDF_Doc/2012/artigo_02_v112012.pdf>. Acesso em: 20 jun. 2015. 